\title{
Lanreotide promotes apoptosis and is not radioprotective in $\mathrm{GH} 3$ cells
}

\author{
Shoucheng Ning ${ }^{1}$, Susan J Knox ${ }^{1}$, Griffith R Harsh ${ }^{2}$, Michael D Culler ${ }^{4}$ \\ and Laurence Katznelson ${ }^{2,3}$
}

Departments of ${ }^{1}$ Radiation Oncology, ${ }^{2}$ Neurosurgery and ${ }^{3}$ Medicine, Stanford University School of Medicine, Stanford University Medical Center, 875 Blake Wilbur Drive, Stanford, California 94305-5821, USA

${ }^{4}$ IPSEN, Milford, Massachusetts 01757, USA

(Correspondence should be addressed to L Katznelson at Departments of Neurosurgery and Medicine, Stanford University School of Medicine, Stanford University Medical Center; Email: Ikatznelson@stanford.edu)

\begin{abstract}
Somatostatin analogs are a mainstay of medical therapy in patients with GH producing human pituitary tumors, and it has been suggested that somatostatin analogs may be radioprotective. We utilized $\mathrm{GH}$ secreting rat $\mathrm{GH} 3$ cells to investigate whether a somatostatin analog may limit the effects of radiation on proliferation and apoptosis in vitro and on tumor growth in vivo. Treatment with lanreotide alone at doses of either 100 or $1000 \mathrm{nM}$ for $48 \mathrm{~h}$ reduced clonogenic survival by $5-10 \%$. Radiation alone produced a dose-dependent survival curve with a SF2 of $48-55 \%$, and lanreotide had no effect on this curve. The addition of lanreotide resulted in a $23 \%$ increase in the proportion of apoptotic sub-G1 cells following irradiation $(P<0.01)$. In a mouse GH3 tumor xenograft model, lanreotide $10 \mathrm{mg} / \mathrm{kg}$ moderately inhibited the growth of $\mathrm{GH} 3$ tumors, with a $4 \times$ tumor growth delay (TGD) time that ranged from 4.5 to 8.3 days. Fractionated local tumor radiation alone significantly inhibited tumor growth and produced a TGD of $35.1 \pm 5.7$ days for 250 cGy fractions. The combination of lanreotide, either antecedent to or concurrent, with radiation of 250,200 or $150 \mathrm{cGy} /$ fraction for 5 days inhibited tumor growth and produced the TGD times that were similar to radiation alone $(P>0.05)$. Pretreatment with lanreotide had the most significant radiosensitizing effect. These studies demonstrate that the somatostatin analog lanreotide is not radioprotective in GH3 cells, and further studies are necessary to determine the impact of lanreotide on apoptosis.
\end{abstract}

Endocrine-Related Cancer (2009) 16 1045-1055

\section{Introduction}

Somatostatin is a peptide hormone that exerts its biologic activity, including inhibition of hormone secretion, by interacting with a family of $G$ protein receptors. Administration of somatostatin analogs, such as lanreotide and octreotide, that interact primarily with the subtype 2 and 5 somatostatin receptors, reduces hormone production in neuroendocrine tumors, such as GH in pituitary somatotroph adenomas (acromegaly) and serotonin in gastrointestinal carcinoid tumors (Lamberts et al. 1996, Arnold et al. 2002, Freda et al. 2005). Clinical studies have also demonstrated that somatostatin analogs can inhibit the growth of a variety of solid tumors, including malignancies of the breast (Weckbecker et al. 1992, Ingle et al. 1996), prostate (Vainas 2001, Koutsilieris et al. 2004), and lung (Bombardieri et al. 1995), though clinical efficacy has been variable (Raderer et al. 1999, Hejna et al. 2002). Somatostatin analogs are a mainstay of medical therapy for a variety of neuroendocrine tumors with regard to reduction in pathologic hormone secretion and inhibition of tumor growth.

Acromegaly is an uncommon disorder characterized by excess secretion of $\mathrm{GH}$, resulting in excessive growth of bone and soft tissues, multi-system co-morbidities, and heightened risk of premature mortality (Ezzat et al. 1994, Ben-Shlomo \& Melmed 2001, Katznelson 2005). Over $90 \%$ of cases of 
acromegaly are caused by adenomatous growth of pituitary somatotroph cells. The preferred treatment for acromegaly is surgical excision, however, adjuvant medical therapy, including somatostatin analogs, and radiation therapy are often necessary for this disease.

Several retrospective, non-controlled studies suggest that somatostatin analogs may be radioprotective in acromegaly (Landolt et al. 2000, Pollock et al. 2002). The anti-proliferative effects of somatostatin analogs on neuroendocrine cells, including human pituitary GH-secreting adenomas in vitro (Miller et al. 1995, Danila et al. 2001, Hubina et al. 2006), may underlie this finding. This raises the issue of whether somatostatin analogs should be maintained during radiation therapy.

To investigate further the question of possible radioprotection by somatostatin analogs, we studied the effects of the somatostatin analog lanreotide on the proliferation and radiosensitivity of $\mathrm{GH}$ producing tumor cells both in vitro and in vivo.

\section{Methods}

\section{Cell culture}

The rat GH3 pituitary tumor cell line was purchased from ATCC (Manassus, VA, USA). Although it would be ideal to use dispersed human pituitary GH-secreting tumor cells in culture for these studies, there are no human pituitary GH-secreting cell lines that can be maintained in a differentiated state in vitro for sufficient time for colony formation assessment (Danila et al. 2000, 2001). GH3 cells were maintained in DMED/F-12 medium (Gibco BRL) supplemented with $10 \%$ FCS, 100 units $/ \mathrm{ml}$ penicillin, and $100 \mu \mathrm{g} / \mathrm{ml}$ streptomycin in a $37{ }^{\circ} \mathrm{C}$ humidified incubator with a mixture of $95 \%$ air and $5 \% \mathrm{CO}_{2}$. All experiments were performed on exponentially growing cells with a doubling time of $\sim 30 \mathrm{~h}$.

\section{In vitro clonogenic assay}

The dose-response of GH3 cells to the treatment of both lanreotide and radiation was characterized using a clonogenic assay. GH3 cells were detached with $0.05 \%$ trypsin-EDTA solution, counted and plated in $60 \mathrm{~mm}$ Petri dishes (BD Biosciences, San Jose, CA, USA) at appropriate dilutions of 100-100 000 cells/dish in triplicate in fresh growth media. Lanreotide (supplied by IPSEN, Milford, MA, USA) was added to the plates at final concentrations of $0-1000 \mathrm{nM}$. Cells were irradiated with $0-10 \mathrm{~Gy}$ at room temperature using a ${ }^{137} \mathrm{Cs}$ source with a dose rate of $300 \mathrm{cGy} / \mathrm{min}$. Following exposure to lanreotide or $\gamma$ radiation, the media was removed, and dishes were washed twice with PBS solution and filled with fresh growth media. After incubation at $37{ }^{\circ} \mathrm{C}$ for 21 days, cells were stained with $0.25 \%$ crystal violet. Colonies containing $\geq 50$ cells were counted under a dissecting microscope and survival curves were generated. The plating efficiency (PE) was calculated as the percentage of cells plated that grew into colonies. The surviving fraction (SF) was defined as the fraction of cells surviving an intervention, i.e. number of colonies/ (number of colonies plated $\times \mathrm{PE}$ ).

For the irradiation experiments, lanreotide at final concentrations of 100 or $1000 \mathrm{nM}$ (determined by experiments shown in Fig. 1) was added at 48, 24, or $0 \mathrm{~h}$ before radiation. Cells were irradiated with $0-10 \mathrm{~Gy}$ in the presence of lanreotide at room temperature with a Cs-137 $\gamma$ irradiator. Following radiation, cells with $24 \mathrm{~h}$ or $0 \mathrm{~h}$ pre-exposure to lanreotide were incubated in lanreotide-containing media for an additional 24 or $48 \mathrm{~h}$ respectively. After a total of $48 \mathrm{~h}$ exposure, lanreotide-containing media was removed, and dishes were washed twice with PBS solution and then filled with fresh growth media. Dishes that were irradiated without lanreotide exposure were also washed twice with PBS and refilled with fresh media. Cells were incubated for 21 days for colony formation.

\section{Apoptosis and cell cycle analysis}

GH3 cells were placed in $60 \mathrm{~mm}$ Petri dishes $(500000$ cells/dish) and grown overnight. Lanreotide at $100 \mathrm{nM}$ was added at $48 \mathrm{~h}, 24 \mathrm{~h}$, or immediately $(0 \mathrm{~h})$ before radiation. Cells were irradiated with 10 Gy $\gamma$ radiation at room temperature. Cells were collected 48, 72, 96, and $168 \mathrm{~h}$ after irradiation, and washed with cold PBS plus $5 \mathrm{mM}$ EDTA. Cells were resuspended in cold PBS-EDTA solution and fixed with cold $100 \%$ ethanol. After incubation for $30 \mathrm{~min}$ at room temperature, cells were pelleted and treated with $100 \mu \mathrm{g} / \mathrm{ml}$ of RNase A in PBS-EDTA solution for $30 \mathrm{~min}$ at room temperature. Propidium iodide (PI) was added to a final concentration of $50 \mu \mathrm{g} / \mathrm{ml}$. The DNA content was analyzed with a FACScan flow cytometer (BD Biosciences). The percentage of cells in the sub-G1 (apoptotic), G1, S, and G2/M phases was calculated. Control cells without any treatment showed a consistent cell cycle distribution within $168 \mathrm{~h}$ (data not shown).

\section{Mouse xenograft tumor model and therapy}

Male nude mice, 8 weeks old and 20-25 $\mathrm{g}$ in body weight, were purchased from Charles River Laboratories (Hollister, CA, USA). Mice were tested and 

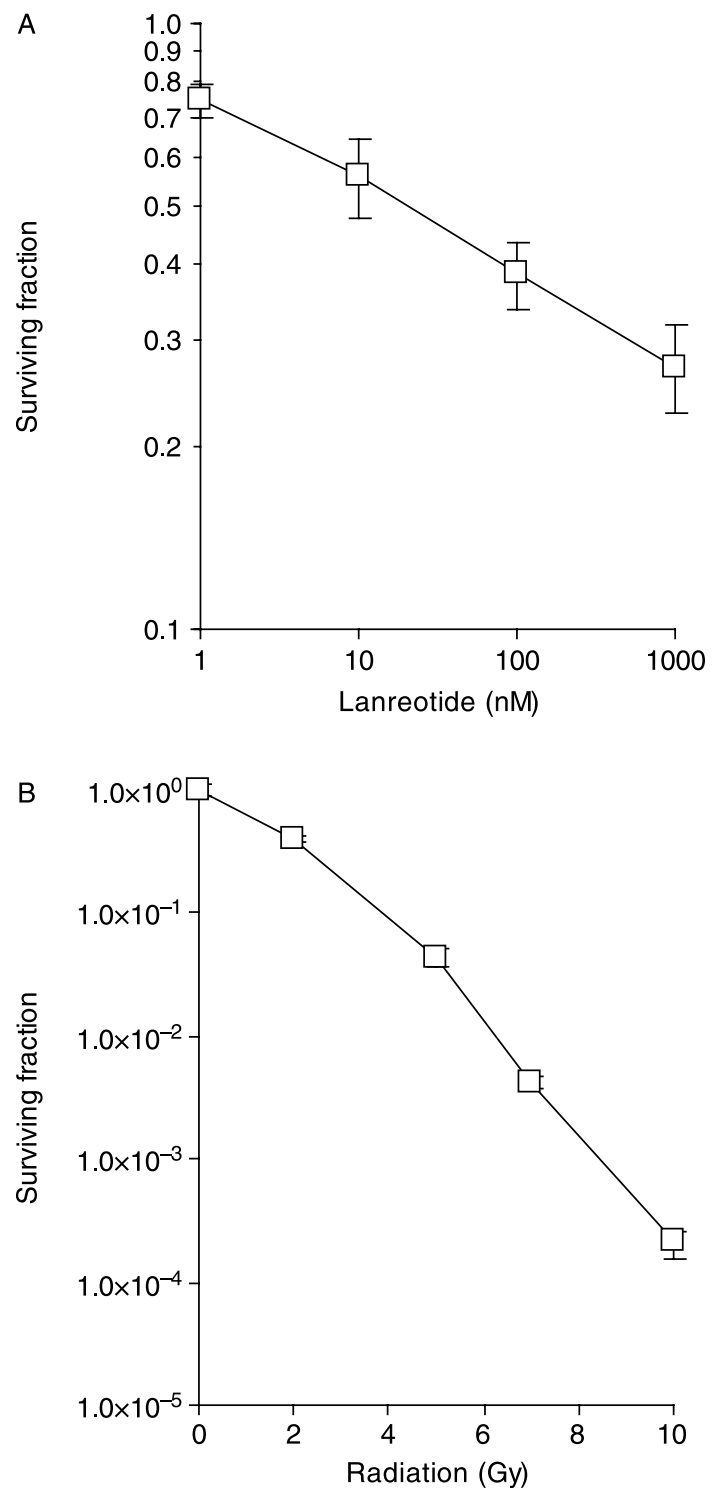

Figure 1 Dose-response of $\mathrm{GH} 3$ cells to $(\mathrm{A})$ lanreotide and (B) $\gamma$ radiation. $\mathrm{GH} 3$ cells were plated in Petri dishes in triplicate and treated with various doses of lanreotide or radiation. Cells were incubated for 21 days for colony formation. Data are presented as surviving fraction against dose on a log-linear plot. Data points represent the mean \pm s.D. of three samples per dose point.

found to be negative for specific pathogens. The mice were normally bred and maintained under specific pathogen-free conditions, and sterilized food and water were available ad libitum. Mice were injected subcutaneously in the right flank with $5 \times 10^{6}$ tumor cells in $100 \mu \mathrm{l}$ of a Hank's solution and Matrigel 1:1 mixture (BD Biosciences). One tumor per mouse was inoculated. When tumors reached an average size of $120 \mathrm{~mm}^{3}\left(80-200 \mathrm{~mm}^{3}\right)$, mice were randomly assigned to the different treatment groups. Five to eight mice were used in each group. Lanreotide was injected s.c. at doses specified in each experiment. For radiation, the unanesthetized tumor-bearing mice were placed in individual lead boxes with tumors protruding through a cutout window at the rear of each box. The radiation was delivered using a Philips RT-250 $200 \mathrm{kVp}$ X-ray unit (12.5 mA; half value Layer, $1.0-\mathrm{mm} \mathrm{Cu}$ ) at a dose rate of $138 \mathrm{cGy} / \mathrm{min}$. Tumors were locally irradiated with a dose of 150-250 cGy per fraction daily for 5 consecutive days as specified in each experiment. The length and width of the tumors were measured with calipers before treatment by the same investigator, and three times a week thereafter until the tumor volume reached at least four times $(4 \times)$ the pretreatment volume. The tumor volume was calculated using the formula: tumor volume $\left(\mathrm{mm}^{3}\right)=\pi / 6 \times$ length $\times$ width $^{2}$. The tumor volume quadrupling $(4 \times)$ time was determined by a best-fit regression analysis. The tumor growth delay (TGD) time (in days) is the difference between the tumor volume quadrupling time of treated tumors compared with that of untreated control tumors. Both the tumor volume quadrupling time and TGD time were calculated for each individual animal and then averaged for each group. In some experiments, a complete regression of tumors was recorded if a tumor completely shrunk to the point that it was not palpable at the end of the experiment. Body weight was measured twice a week. The mouse experiments described herein were approved by the Stanford University Administrative Panel for Laboratory Animal Care.

\section{Statistical analysis}

The significance of differences between mean values obtained for the various study endpoints was calculated using an unpaired Student's $t$-test.

\section{Results}

\section{In vitro experiments}

\section{Dose-responses of GH3 cells to lanreotide and $\gamma$ radiation}

As shown in Fig. 1A, treatment with lanreotide resulted in a dose-dependent decrease in GH3 cell colony forming units. Lanreotide at doses of 1, 10, 100, and $1000 \mathrm{nM}$ resulted in cell survival rates of 75, 56, 39 and $27 \%$ respectively. The IC50 (50\% inhibition of cell growth) was $57 \mathrm{nM}$. The radiation survival curves are shown in Fig. 1B. GH3 cells had a typical radiation dose-response survival curve with an initial shoulder at 
doses below $5 \mathrm{~Gy}$ and a straight line at high dose. The SF at 2 Gy (SF2, a dose commonly used in daily fractionated radiotherapy) was $40 \%$.

\section{Effect of lanreotide on radiation response of GH3 cells}

GH3 cells were plated in tissue culture dishes overnight. The radiation survival curves are shown in Fig. 2. Treatment with lanreotide alone at doses of either 100 or $1000 \mathrm{nM}$ for $48 \mathrm{~h}$ without radiation reduced clonogenic survival compared with untreated controls by $5-10 \%$. Radiation alone without lanreotide produced a dose-dependent survival curve with a SF2 of $48-55 \%$. Treatment with lanreotide at a dose of $100 \mathrm{nM}$ for $48 \mathrm{~h}$ either before $(48 \mathrm{~h}$ prelanreotide and $24 \mathrm{~h}$ prelanreotide) or at the time of radiation $(0 \mathrm{~h}$ prelanreotide) produced survival curves that were slightly shifted downward and separated at doses of 7-10 Gy from the survival curve produced by radiation alone without lanreotide (Fig. 2A) indicating that the radiation response of $\mathrm{GH} 3$ cells was enhanced by lanreotide. The SF at $10 \mathrm{~Gy}$ was $0.0006,0.00022$, 0.00040 , and 0.00042 respectively, for radiation alone, $48 \mathrm{~h}$ pre-, $24 \mathrm{~h}$ pre- and $0 \mathrm{~h}$ pre-exposure to lanreotide (Fig. 2C). However, treatment with $1000 \mathrm{nM}$ lanreotide did not alter the shape and slopes of the radiation survival curves, indicating there was no radioprotection (or radiosensitization) effect under these experimental conditions (Fig. 2B).

\section{Effect of lanreotide and radiation on apoptosis and cells cycle distribution}

The percentage of cells in sub-G1, G1, S, and G2/M phases at $48 \mathrm{~h}$ was $1.4 \pm 0.2,73.2 \pm 1.0,8.4 \pm 1.0$, and $16.9 \pm 1.8 \%$ respectively. Treatment with $100 \mathrm{nM}$ lanreotide alone resulted in the sub-G1, G1, S, and $\mathrm{G} 2 / \mathrm{M}$ phase distribution of $2.28 \pm 0.3,73.8 \pm 1.1$, $7.72 \pm 0.8$, and $16.2 \pm 0.5 \%$ respectively, indicating that the cell cycle profile was not significantly affected by treatment with lanreotide compared with the untreated control, except for a moderate increase in apoptotic sub-G1 cells from 1.4 to $2.28 \%$. Treatment with $10 \mathrm{~Gy}$ radiation resulted in a decrease in the proportion of cells in G1 phase from 73.2 to $51.5 \%$ at $48 \mathrm{~h}$. Meanwhile, the $\mathrm{G} 2 / \mathrm{M}$ phase cells increased from $16.9 \%$ before radiation to $35.7 \%$ at $48 \mathrm{~h}$ after irradiation, and cells were arrested at $\mathrm{G} 2 / \mathrm{M}$ phase for up to $168 \mathrm{~h}$ without release. The subdiploid cell population, representing apoptotic cells, increased steadily following radiation from a baseline of $1.4 \%$ to a peak of $\sim 12 \%$ at $168 \mathrm{~h}$ (Fig. 3). Combined treatment of GH3 cells with radiation and lanreotide
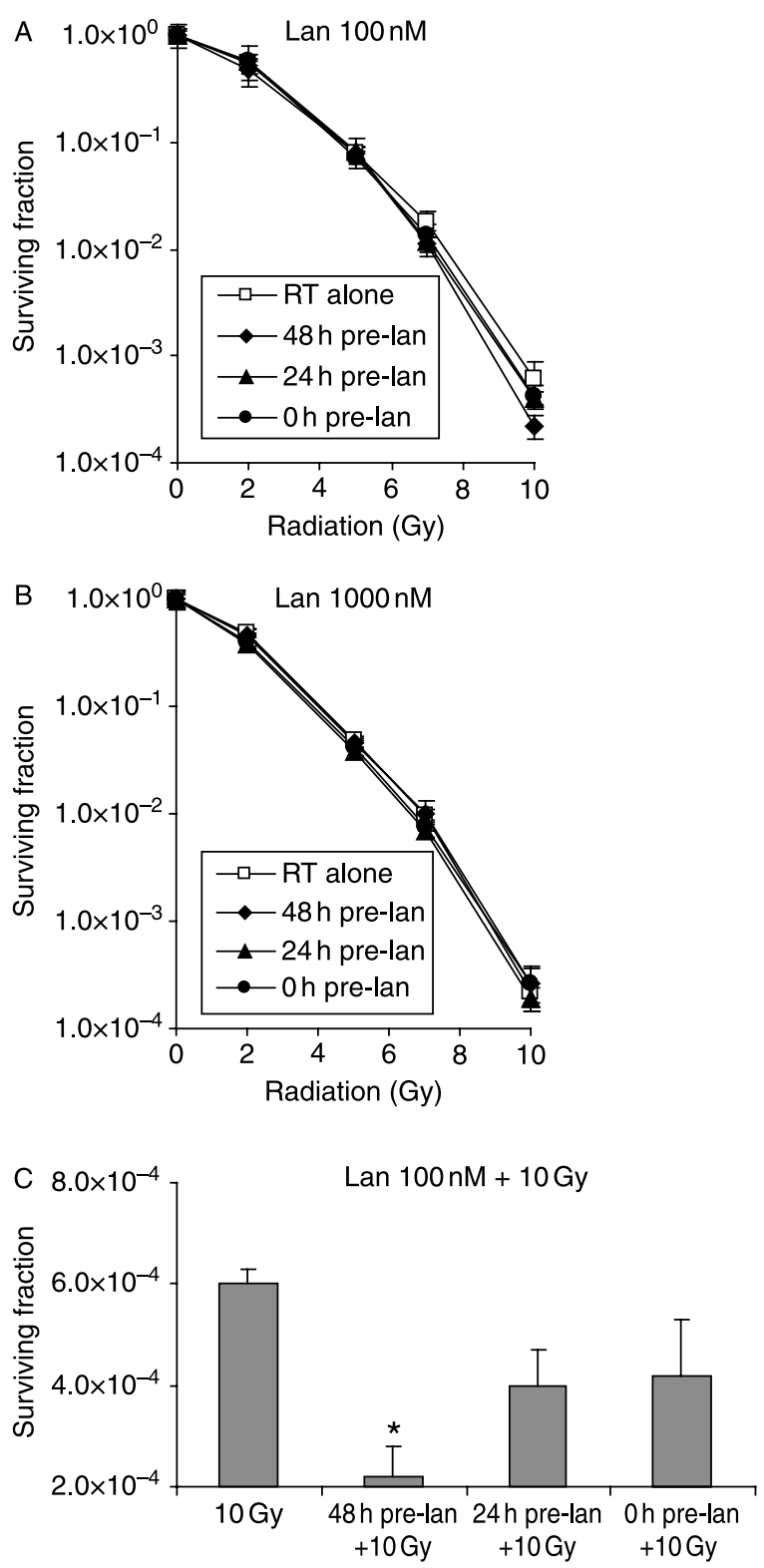

Figure 2 Radiation survival curves for GH3 cells treated with radiation alone or in the presence of lanreotide at doses of (A) $100 \mathrm{~nm}$ or (B) $1000 \mathrm{nM}$. Lanreotide (Lan) was given 48 or $24 \mathrm{~h}$ prior to or immediately $(0 \mathrm{~h})$ before radiation (0-10 Gy). The total exposure time for lanreotide was $48 \mathrm{~h}$. For $(A)$ and $(B)$ : open squares, radiation (RT) alone; solid diamonds, lanreotide administrated $48 \mathrm{~h}$ pre-RT; solid triangles, lanreotide administrated $24 \mathrm{~h}$ pre-RT; solid circles, lanreotide administrated immediately before RT ( $0 \mathrm{~h}$ ). (C) Radiation survival of $\mathrm{GH} 3$ cells treated with 10 Gy radiation with or without $100 \mathrm{nM}$ lanreotide. Data represent the mean \pm s.D. from two experiments. ${ }^{\star} P<0.01$ compared with $10 \mathrm{~Gy}$ radiation alone.

produced a cell cycle profile that was similar to that seen in irradiated cells without lanreotide, except for the increase in apoptotic sub-G1 proportion. As shown in Fig. 3, at $48 \mathrm{~h}$ after irradiation, the apoptotic sub-G1 
A Time after radiation exposure
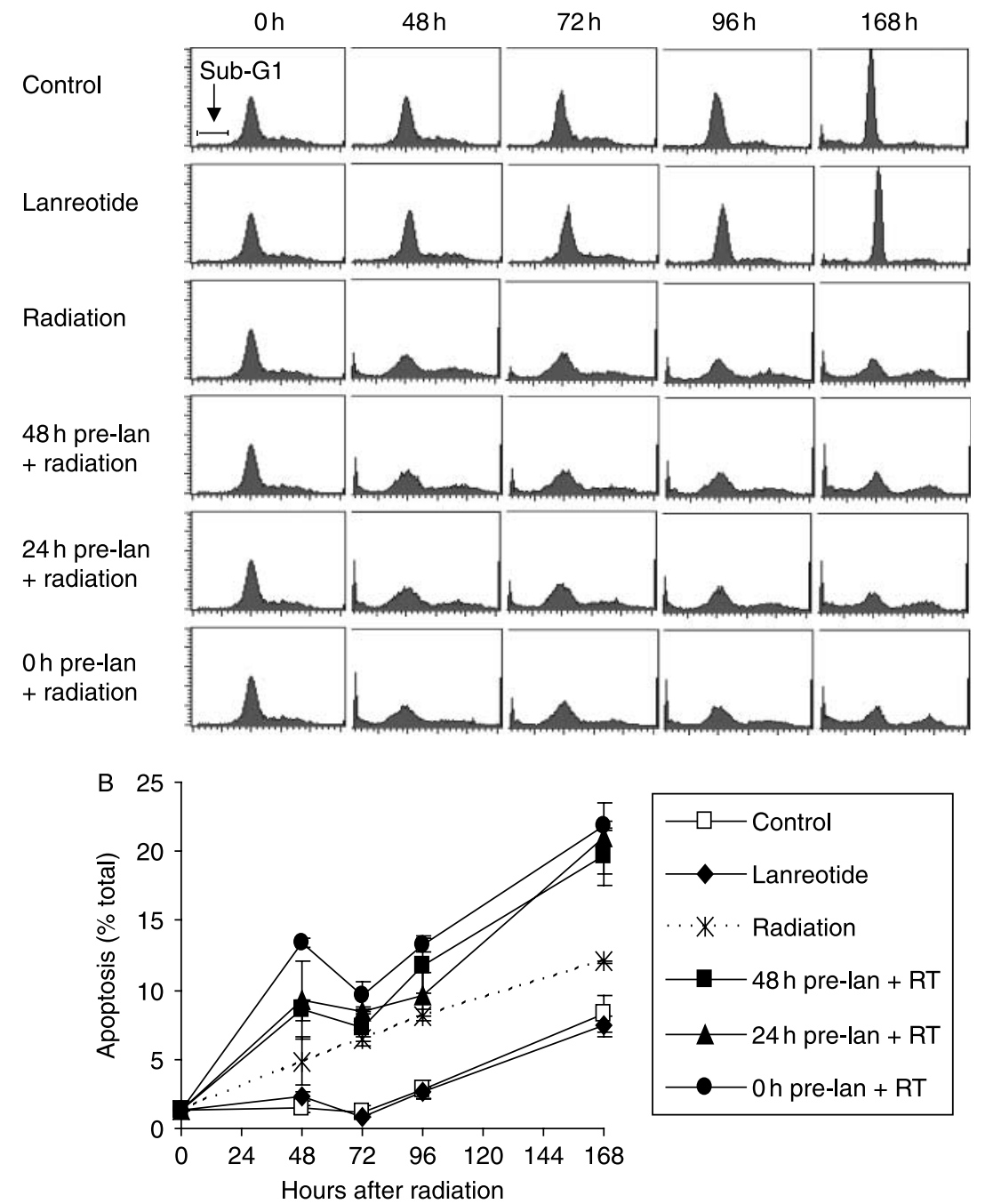

Figure 3 Cell cycle redistribution of GH3 cells after irradiation in the absence or presence of lanreotide. Lanreotide at $100 \mathrm{nM}$ was added to the media either $48,24 \mathrm{~h}$ or immediately $(0 \mathrm{~h})$ before radiation and kept in the media until collection of samples. The cell cycle was analyzed using FACScan flow cytometer. (A) Cell cycle histogram from FASCan flow cytometer. (B) Percent of cells in apoptotic sub-G1 phase of the cell cycle after irradiation $(0-168 \mathrm{~h})$.

cells increased from $4.9 \%$ for radiation alone to 8.6 , 9.3 , and $13.4 \%$ for the combination of radiation with 48,24 , and $0 \mathrm{~h}$ pre-exposure of lanreotide respectively, representing an increase of $77-173 \%$ compared with radiation alone $(P<0.01)$. At $168 \mathrm{~h}$ after radiation, the sub-G1 cell fraction was $12 \%$ for radiation alone and $20-22 \%$ for radiation plus lanreotide, representing an increase of $67-83 \%(P<0.01)$.

\section{In vivo experiments}

\section{Dose-responses of GH3 tumors to lanreotide}

Groups of nude mice with established GH3 xenograft tumors were treated subcutaneously with $2.5,5,10,20$, or $50 \mathrm{mg} / \mathrm{kg}$ lanreotide daily for 5 days. Doses were based on prior studies utilizing lanreotide administration in vivo (Prevost et al. 1994, Melen-Mucha et al. 2004). As shown in Fig. 4, there was a bell-shaped dose dependent effect of lanreotide on GH3 tumor growth, with a narrow range of optimal doses. The maximum tumor growth inhibition (i.e. the longest TGD time of $13.1 \pm 4.7$ days) occurred with a daily lanreotide dose of $10 \mathrm{mg} / \mathrm{kg}$. When the daily lanreotide dose was either higher (i.e. 20 and $50 \mathrm{mg} / \mathrm{kg}$ ) or lower $(2.5$ and $5 \mathrm{mg} / \mathrm{kg}$ ) than $10 \mathrm{mg} / \mathrm{kg}$, the effects of lanreotide on GH3 tumor growth were diminished.

In these studies, lanreotide at all doses tested did not cause significant decrease in body weight compared 


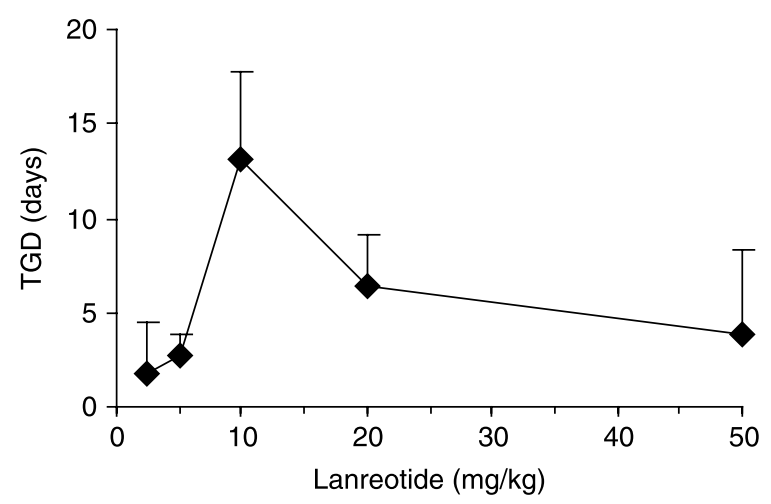

Figure 4 Dose-response of $\mathrm{GH} 3$ xenograft tumors to lanreotide. GH3 tumor-bearing mice were injected with 2.5, 5, 10,20 , or $50 \mathrm{mg} / \mathrm{kg}$ lanreotide daily for 5 days. The $4 \times$ tumor growth delay (TGD) times were calculated for each tumor and averaged for each dose point. Data are presented as TGD in days as a function of dose. Data points represent the mean \pm s.D. of two experiments.

with untreated control mice (data not shown). Also, there was no notable change in the general appearance and daily activity of tumor-bearing mice treated with lanreotide.

\section{Comparison of lanreotide dose regimen of once daily versus twice daily}

To determine the importance of lanreotide dose regimen on tumor growth, we compared tumor size after single daily dose (qd) and two doses daily (bid). GH3 tumor-bearing nude mice were injected s.c. with lanreotide at doses of $2.5,5$ or $10 \mathrm{mg} / \mathrm{kg}$ for 5 days either once daily or twice daily ( $8 \mathrm{~h}$ interval). As shown in Fig. 5, there were no statistically significant differences between groups treated either once daily or twice daily at the same dose $(P=0.3-0.9)$. However, lanreotide at $10 \mathrm{mg} / \mathrm{kg}$ once daily produced the longest

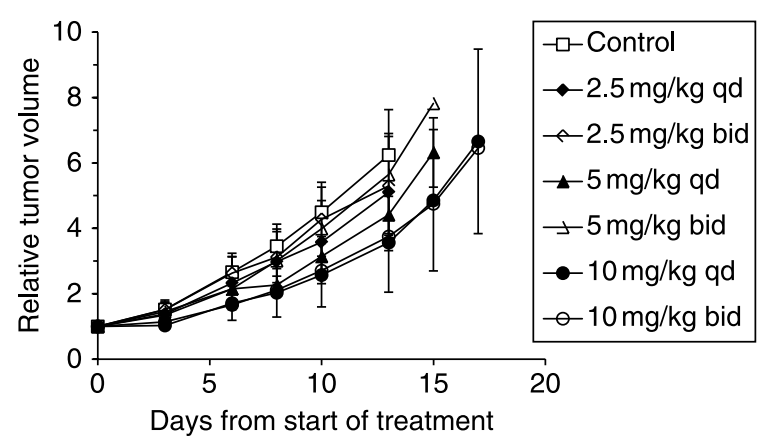

Figure 5 Tumor growth curves of mice with $\mathrm{GH} 3$ tumors treated with lanreotide at doses of $2.5,5$, or $10 \mathrm{mg} / \mathrm{kg}$ once daily (qd) or twice daily (bid). Data are presented as the average tumor volume of each group (mean \pm S.D.) versus time from start of treatment.
TGD time $(4.9 \pm 2.1$ days $)$ of all dose regimens studied $(P<0.05)$. Notably, this was longer than that $(1.1 \pm 3.1$ days) following $5 \mathrm{mg} / \mathrm{kg}$ twice daily. Analogously, a single daily dose of $5 \mathrm{mg} / \mathrm{kg}$ qd produced a longer TGD time than did $2.5 \mathrm{mg} / \mathrm{kg}$ bid. These data suggest that a single dose of lanreotide produced at least as much tumor growth inhibition than a fractionated dose regimen at the same total daily dose. Therefore, further studies utilized the single daily dosing regimen.

\section{Combination therapy of lanreotide and fractionated radiation}

To study the effect of lanreotide on tumor responses to radiation therapy, nude mice with established GH3 tumors were treated with: 1) $10 \mathrm{mg} / \mathrm{kg}$ lanreotide daily for 5 days; 2) local tumor radiation daily for 5 consecutive days at doses of 250,200 , or $150 \mathrm{cGy} /$ fraction per day; 3) a combination of lanreotide and local tumor radiation as above; or 4) a s.c. injection of normal saline $(0.005 \mathrm{ml} / \mathrm{g}$ body weight) daily as an untreated control. In combination therapy, lanreotide was injected $20 \mathrm{~min}$ before radiation. Data are shown in Fig. 6 (tumor growth curves). Lanreotide alone at a dose of $10 \mathrm{mg} / \mathrm{kg}$ moderately inhibited the growth of GH3 tumors, with a $4 \times$ TGD time that ranged from 4.5 to 8.3 days $(P=0.3-0.06$, compared with the relevant control groups). Fractionated local tumor radiation alone significantly inhibited tumor growth and produced TGD times of $35.1 \pm 5.7$ days for $250 \mathrm{cGy}$ fractions, $21.7 \pm 5.5$ days for $200 \mathrm{cGy}$ fractions, and $16.7 \pm 1.7$ days for $150 \mathrm{cGy}$ fractions respectively. The combination of lanreotide with radiation of 250,200 , or $150 \mathrm{cGy} /$ fraction for 5 days inhibited tumor growth and produced the TGD times that were similar to radiation alone $(P>0.05)$. Also, the combined treatment of lanreotide and fractionated radiation did not cause any further decrease in animal body weight compared with fractionated radiation therapy alone.

\section{Preadministration of lanreotide in combination with radiation therapy}

To study whether preadministration of lanreotide could modulate radiation effects on tumor growth, nude mice with GH3 xenograft tumors were treated with: 1) $10 \mathrm{mg} / \mathrm{kg}$ lanreotide daily for 10 days; 2) $150 \mathrm{cGy}$ local tumor radiation daily for 5 consecutive days; and 3 ) $10 \mathrm{mg} / \mathrm{kg}$ lanreotide for 5 days followed by combined administration of lanreotide and $150 \mathrm{cGy}$ radiation daily for 5 days. A group of tumor-bearing mice that was injected s.c. with normal saline daily for 10 days 

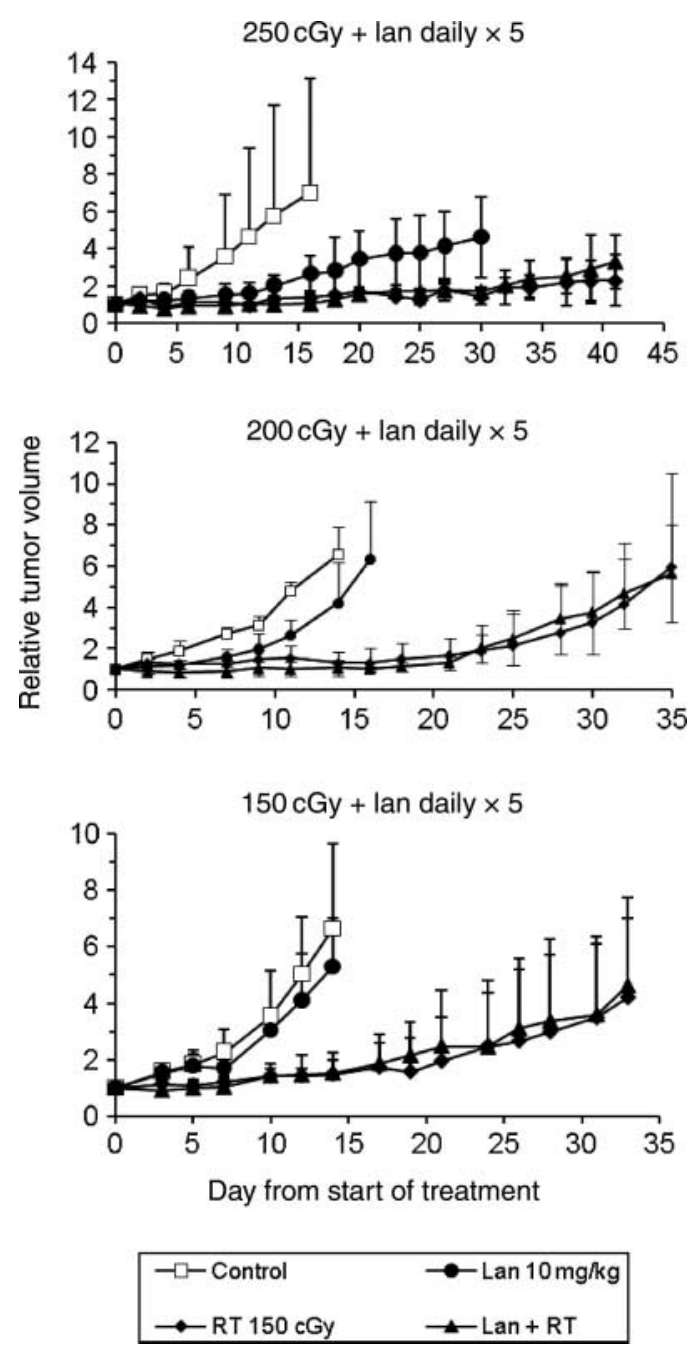

Figure 6 Tumor growth curves of GH3 tumor mice after combined treatment with lanreotide and fractionated local tumor radiation. Lanreotide (Lan) was injected subcutaneously (s.c.) at $10 \mathrm{mg} / \mathrm{kg}$ daily for 5 days. Radiation was delivered locally to the tumor at a daily dose of 250 (top), 200 (middle), or 150 (bottom) cGy for 5 days. There were four groups in each study: 1) untreated control, open squares; 2) lanreotide alone, solid circles; 3) radiation alone, solid diamonds; and 4) combination of lanreotide and radiation, solid triangles. Six to eight animals were used in each group. Data are presented as the relative tumor volume: this consists of the ratio of tumor volume of each group (mean \pm S.D.) compared with baseline tumor volume.

was also included as an untreated control. As shown in Fig. 7, lanreotide at a dose of $10 \mathrm{mg} / \mathrm{kg}$ for 10 days moderately inhibited tumor growth $(4 \times$ TGD, $8.3 \pm 8.3$ days, $P=0.06$ versus control). Local tumor radiation of $150 \mathrm{cGy}$ inhibited tumor growth and gave a TGD time of $15.5 .0 \pm 8.8$ days $(P<0.05$ versus control and lanreotide alone). The combination therapy of preadministration of lanreotide and radiation in this treatment regimen resulted in a TGD time of $15.1 \pm 8.6$ days, similar to that produced by radiation
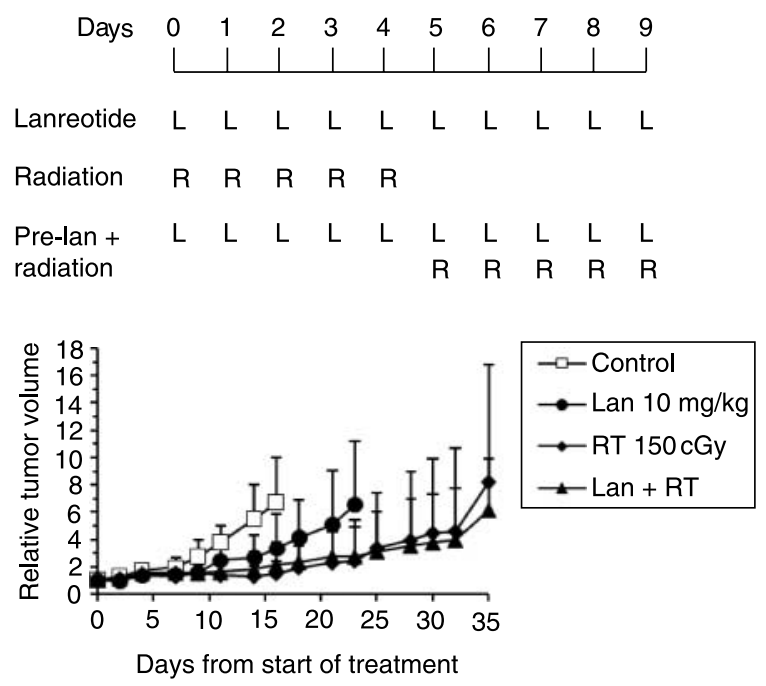

Figure 7 Tumor growth curves of mice with GH3 tumor treated with lanreotide and fractionated radiation. Lanreotide (Lan) was injected at a dose of $10 \mathrm{mg} / \mathrm{kg}$ daily for 10 days. Radiation was delivered locally to the tumor at a daily dose of 150 cGy for 5 days. There were four groups: 1) untreated control, open squares; 2) lanreotide alone, solid circles; 3) radiation alone, solid diamonds; and 4) combination of lanreotide and radiation, solid triangles. Six animals were used in each group. The treatment paradigm is shown on top. Data are presented on the bottom as the relative tumor volume: this consists of the ratio of tumor volume of each group (mean \pm S.D.) compared with baseline tumor volume.

therapy alone $(15.5 \pm 8.8$ days; $P>0.05)$. There were two mice with complete regression of tumors in both radiation alone and combination therapy groups, without tumor regrowth when the study was terminated after 60 days. Furthermore, lanreotide alone and in combination with radiation did not produce any obvious signs of systemic toxicity in terms of the loss of body weight, general appearance, skin reaction or activity level of the mice (data not shown).

\section{Discussion}

Administration of somatostatin analogs, such as lanreotide and octreotide, interact primarily with the subtype 2 and 5 somatostatin receptors and reduce hormone production in neuroendocrine tumors, such as GH in pituitary somatotroph adenomas that are associated with acromegaly (Lamberts et al. 1996, Arnold et al. 2002, Freda et al. 2005).

In an in vitro study of 18 human pituitary somatotroph adenomas, administration of somatostatin and its analogs inhibited proliferation in $\sim 30 \%$ of tumors (Danila et al. 2001). In this study, antiproliferative and anti-GH secretory activity did not always correlate, suggesting that the effects of 
somatostatin analogs on these biologic effects may be independent. Mechanisms underlying these anti-proliferative effects may include up-regulation of the cyclin-dependent kinase inhibitor $\mathrm{p} 27$, inhibition of the MAP kinase pathway, mobilization of calcium, inhibition of PI3K/Akt survival signal and induction of the tumor suppressor Zac1 (Cheung \& Boyages 1995, Danila et al. 2001, Hubina et al. 2006, Theodoropoulou et al. 2006).

To study the effects of somatostatin analogs and radiation on tumor proliferation, it would be optimal to utilize human GH producing pituitary adenoma cells. However, dispersed human pituitary tumor cells are difficult to maintain for prolonged passages in culture (Danila et al. 2000, 2001). Studies have successfully utilized human fetal pituitary cells (Shimon et al. 1997), though this model is not representative of an adenoma cell line. Given the limitations of such models, we utilized rat GH3 cells because they express somatostatin receptors and are somatostatin responsive (Dasgupta et al. 1999). In addition, these cells grow well in culture and may be used in a xenograft tumor model. However, GH3 cells differ from human somatotroph cells in lacking functional GHRH receptors and expression of the somatostatin receptor subtypes (Zeytin et al. 1984, Garcia \& Myers 1994). Therefore, GH3 cells are not a precise model for investigating human pituitary disease, but these cells are relevant for such investigations and are highly useful when used in a model to demonstrate effects of somatostatin analogs on neuroendocrine tumor proliferation and growth.

In our study in vitro in rat GH3 cells, lanreotide had a dose-related anti-proliferative effect, with an IC50 of $57 \mathrm{nM}$, in a colony formation assay. These results are similar to findings in another study using octreotide in GH3 cells using flow cytometric DNA analysis with PI staining (Cheung \& Boyages 1995). In contrast, our findings differ from those of a previous study in GH3 cells in which octreotide did not show a dose-response anti-proliferative curve, in that $1000 \mathrm{nM}$ octreotide had reduced activity as compared with $100 \mathrm{nM}$ octreotide (Pelicci et al. 1990). In the previous study, cells were exposed to octreotide for $24 \mathrm{~h}$, and the MTT assay was used. In contrast, we utilized the clonogenic assay, which may be more sensitive and reliable, and exposed the cells to lanreotide for a longer time; thus, potentially explaining our different findings. Of note, in our study, treatment with lanreotide did not change the cell cycle profile, in contrast to the production of partial G0/G1 cell cycle block reported by others (Cheung \& Boyages 1995). Cheung \& Boyages (1995) found the effect of octreotide on cell cycle arrest to be transient, lasting only $36-48 \mathrm{~h}$. In our study, cells were treated for $48 \mathrm{~h}$ with lanreotide. It is possible that the difference between our results and those of Cheung \& Boyages may reflect differences in the time of exposure to lanreotide, or differences in the action of lanreotide and octreotide.

Although lanreotide alone reduced proliferation of GH3 cells in a dose-responsive manner, lanreotide administration either before or during radiation had no effect on radiation survival in vitro. This is similar to a recent finding in another study (Rezacova et al. 2008). In fact, treatment with lanreotide at a dose of $100 \mathrm{nM}$ for $48 \mathrm{~h}$ tended to shift the survival curves downward and increased the apoptotic cell population at the high doses of radiation. This suggests that lanreotide may synergistically enhance the radiation response of GH3 cells when combined with high dose radiation, such as that delivered clinically by stereotactic radiosurgery (SRS). Our data do not support a radioprotective effect of somatostatin analogs.

We utilized a mouse GH3 xenograft model to assess further both the anti-proliferative effects of lanreotide and the potential effects of lanreotide on proliferation following radiation. Administration of lanreotide alone for 10 days resulted in moderate inhibition of tumor growth. This observation validated use of this model to assess the effects of somatostatin analogs on pituitary tumor cell proliferation. Lanreotide was well tolerated, as evidence by the continued growth and weight of the animals. The anti-proliferative effect of lanreotide was observed irrespective of whether lanreotide was administered daily or as a split-daily dose, suggesting that anti-proliferative effects depend on the absolute daily dose, not the dose regimen. Of note, the antiproliferative effects had a bell-shaped dose effect, similar to that described previously with somatostatin analog administration in vitro with $\mathrm{GH} 3$ cells (Hubina et al. 2006). These data suggest that there may be a narrow range of doses that are optimal for maximizing the anti-proliferative effects of lanreotide.

The results presented here also demonstrate that co-administration of lanreotide with radiation at a variety of doses did not affect radiation response of GH3 tumors in vivo. In fact, several tumor-bearing mice in both the radiation and radiation plus lanreotide groups attained complete remission of tumors, which did not occur in the groups treated with lanreotide alone. These data suggest that somatostatin analogs, when administered at doses that produce a modest antiproliferative effect in rat GH3 tumor model, are not radioprotective. Our data are also suggestive that administration of lanreotide prior to and during radiotherapy is more effective than administration of 
lanreotide during radiotherapy alone in reducing tumor volume, though we did not test this finding in a single experiment. Nevertheless, this finding is suggestive that administration of lanreotide prior to radiotherapy, which is reflective of clinical practice in humans, is highly effective at adding to radiation effects in reducing tumor volume. Further studies of different somatostatin analog dosing regimens are needed to optimize the dosing of lanreotide when given in combination with radiation therapy. These studies are necessary to further confirm our initial findings that lanreotide does not radioprotect pituitary tumors in vivo. In addition, our studies may suggest paradigms for investigation of radiosensitizing effects of somatostatin analogs in pituitary and other tumor models.

In our study, lanreotide enhanced radiation-induced apoptosis in GH3 pituitary tumor cells. The apoptotic subdiploid cell population increased steadily following exposure to $10 \mathrm{~Gy}$ radiation and $100 \mathrm{nM}$ lanreotide, indicating a super-additive effect on apoptosis with combined use of lanreotide and radiation. The mechanism of action by which lanreotide enhances radiation-induced apoptosis has not been elucidated. Previous studies have demonstrated that somatostatin analogs can up-regulate proapoptotic genes p53 (Sharma et al. 1996), death receptors (Guillermet et al. 2003), and BAX (Sharma \& Srikant 1998), and down-regulate anti-apoptotic bcl-2 (Guillermet et al. 2003).

p53 is the most commonly altered gene in human cancer. Inresponse to DNA damage, p53 activates genes leading to apoptosisand cell cycle arrest. Even though lanreotide did not affect the cell cycle distribution, and blocks cells at G1 phase in our study, one cannot exclude a role for p53 in lanreotideinduced apoptosis in GH3 cells. In a previous report (28), Sharma et al. showed that the somatostatin analog, octreotide, induces wild-type p53-associated apoptosis without G1 cell cycle arrest in $\mathrm{CHO}$ cells. The tumor necrosis factor-related apoptosis-inducing ligand (TRAIL) is a powerful apoptosis inducer. TRAIL induces apoptosisthrough activating its proapoptotic death receptor and effector caspase 3 (Ashkenazi \& Dixit 1998, Luciani et al. 2005), independent of mitochondria (i.e. extrinsic pathway; Scaffidi et al. 1998). Radiation induces apoptosis mostly via the mitochondrial signal pathway (i.e. intrinsic pathway), an effect which can be blocked by over-expression of bcl-2. Since radiationand somatostatin analogs induce apoptosis in tumor cells throughdifferent signaling pathways, combination of the two modalitiesmay lead to synergistic effect on apoptotic cell death. Furthermore, it has reported that somatostatin analogs inhibit the expression and secretion of the growth factors, such as insulin-like growth factor-1 (IGF-1), vascular endothelial growth factor (VEGF), and basic fibroblast growth factor (bFGF), in tumor cells (Baldysiak-Figiel et al. 2005, Kanashiro et al. 2005). Since ionizing radiation activates and/or induces the overexpression of VEGF, bFGF and other growth factors in tumor cells (Kim et al. 2006), combined use of lanreotide and ionizing radiation could inhibit the pro-survival autocrine and paracrine effects of these radiation-induced growth factors in targeted tumor cells.

Our experimental paradigm may serve as a model to assess the radioprotective qualities of somatostatin analogs in acromegaly. Radiation therapy is often utilized as adjuvant therapy for persistent, active disease following incomplete surgery (Castinetti et al. 2005, Jenkins et al. 2006). Because patients are often symptomatic at the time of radiation therapy, somatostatin analogs are often administered in conjunction with radiation. However, there has been concern that the anti-proliferative effects of somatostatin analogs may protect the tumor cells from the tumoricidal effects of radiation. In a retrospective study, Landolt et al. (2000) assessed the effects of $\gamma$ knife SRS in 31 subjects with acromegaly, nine of whom received octreotide at the time of radiation. Following SRS, a smaller fraction of the patients treated with octreotide at the time of SRS achieved biochemical remission. The nonsignificant trend for higher GH and IGF-1 levels in subjects who required octreotide, suggests that the difference in response to SRS may reflect more aggressive disease in the subjects receiving octreotide. In contrast, the use of octreotide at the time of $\gamma$ knife SRS did not affect biochemical outcomes in 82 subjects with acromegaly in another study (Castinetti et al. 2005). Nevertheless, the question as to whether somatostatin analogs should be withheld at the time of radiation therapy remains controversial. Our findings in an animal model suggest that somatostatin analogs may in fact be radiosensitizing, a finding that clearly deserves more study.

In summary, using a mouse xenograft model, we have demonstrated that the somatostatin analog lanreotide does not protect pituitary tumor cells from the effects of ionizing radiation, but does promote radiation induced apoptosis in rat GH3 cells. Further studies, both in vitro and in vivo, are needed to determine the potential clinical relevance of these findings to the management of patients with neuroendocrine tumors, such as acromegaly, and whether somatostatin analogs should be administered concurrently with radiation therapy. These preliminary 
findings also suggest that lanreotide may enhance radiation-induced apoptosis and warrant further study.

In addition, further studies are necessary to elucidate the mechanisms underlying this potential synergistic action of lanreotide and radiation on apoptosis induction.

\section{Declaration of interest}

S Ning, S Knox, and G Harsh report no conflict of interest. L Katznelson is on the speaker's bureau at Tercica-IPSEN. M D Culler is employed by IPSEN.

\section{Funding}

Supported in part by a research grant from IPSEN.

\section{References}

Arnold R, Wied M \& Behr TH 2002 Somatostatin analogues in the treatment of endocrine tumors of the gastrointestinal tract. Expert Opinion on Pharmacotherapy 3 643-656.

Ashkenazi A \& Dixit VM 1998 Death receptors: signaling and modulation. Science 281 1305-1308.

Baldysiak-Figiel A, Jong-Hesse YD, Lang GK \& Lang GE 2005 Octreotide inhibits growth factor-induced and basal proliferation of lens epithelial cells in vitro. Journal of Cataract and Refractive Surgery 31 1059-1064.

Ben-Shlomo A \& Melmed S 2001 Acromegaly. Endocrinology and Metabolism Clinics of North America 30 565-583 vi.

Bombardieri E, Crippa F, Cataldo I, Chiti A, Seregni E, Soresi E, Boffi R, Invernizzi G \& Buraggi GL 1995 Somatostatin receptor imaging of small cell lung cancer (SCLC) by means of 111In-DTPA octreotide scintigraphy. European Journal of Cancer 31A 184-188.

Castinetti F, Taieb D, Kuhn JM, Chanson P, Tamura M, Jaquet P, Conte-Devolx B, Réqis J, Dufour H, Brue T et al. 2005 Outcome of gamma knife radiosurgery in 82 patients with acromegaly: correlation with initial hypersecretion. Journal of Clinical Endocrinology and Metabolism 90 4483-4488.

Cheung NW \& Boyages SC 1995 Somatostatin-14 and its analog octreotide exert a cytostatic effect on $\mathrm{GH} 3$ rat pituitary tumor cell proliferation via a transient G0/G1 cell cycle block. Endocrinology 136 4174-4181.

Danila DC, Zhang X, Zhou Y, Dickersin GR, Fletcher JA, Hedley-Whyte ET, Selig MK, Johnson SR \& Klibanski A 2000 A human pituitary tumor-derived folliculostellate cell line. Journal of Clinical Endocrinology and Metabolism 85 1180-1187.

Danila DC, Haidar JN, Zhang X, Katznelson L, Culler MD \& Klibanski A 2001 Somatostatin receptor-specific analogs: effects on cell proliferation and growth hormone secretion in human somatotroph tumors. Journal of Clinical Endocrinology and Metabolism 86 2976-2981.
Dasgupta P, Singh AT \& Mukherjee R 1999 Antiproliferative and GH-inhibitory activity of chimeric peptides consisting of GHRP-6 and somatostatin. Biochemical and Biophysical Research Communications 259 379-384.

Ezzat S, Forster MJ, Berchtold P, Redelmeier DA, Boerlin V \& Harris AG 1994 Acromegaly. Clinical and biochemical features in 500 patients. Medicine 73 233-240.

Freda PU, Katznelson L, van der Lely AJ, Reyes CM, Zhao S \& Rabinowitz D 2005 Long-acting somatostatin analog therapy of acromegaly: a meta-analysis. Journal of Clinical Endocrinology and Metabolism 90 4465-4473.

Garcia PD \& Myers RM 1994 Pituitary cell line GH3 expresses two somatostatin receptor subtypes that inhibit adenylyl cyclase: functional expression of rat somatostatin receptor subtypes 1 and 2 in human embryonic kidney 293 cells. Molecular Pharmacology 45 402-409.

Guillermet J, Saint-Laurent N, Rochaix P, Cuvillier O, Levade T, Schally AV, Pradayrol L, Buscail L, Susini C \& Bousquet C 2003 Somatostatin receptor subtype 2 sensitizes human pancreatic cancer cells to death ligandinduced apoptosis. PNAS 100 155-160.

Hejna M, Schmidinger M \& Raderer M 2002 The clinical role of somatostatin analogues as antineoplastic agents: much ado about nothing? Annals of Oncology 13 653-668.

Hubina E, Nanzer AM, Hanson MR, Ciccarelli E, Losa M, Gaia D, Papotti M, Terreni MR, Khalaf S, Jordan S et al. 2006 Somatostatin analogues stimulate p27 expression and inhibit the MAP kinase pathway in pituitary tumours. European Journal of Endocrinology 155 371-379.

Ingle JN, Kardinal CG, Suman VJ, Krook JE \& Hatfield AK 1996 Octreotide as first-line treatment for women with metastatic breast cancer. Investigational New Drugs 14 235-237.

Jenkins PJ, Bates P, Carson MN, Stewart PM \& Wass JA 2006 Conventional pituitary irradiation is effective in lowering serum growth hormone and insulin-like growth factor-I in patients with acromegaly. Journal of Clinical Endocrinology and Metabolism 91 1239-1245.

Kanashiro CA, Schally AV, Nagy A \& Halmos G 2005 Inhibition of experimental U-118MG glioblastoma by targeted cytotoxic analogs of bombesin and somatostatin is associated with a suppression of angiogenic and antiapoptotic mechanisms. International Journal of Oncology 27 169-174.

Katznelson L 2005 Diagnosis and treatment of acromegaly. Growth Hormone and IGF Research 15 S31-S35.

Kim DW, Huamani J, Fu A \& Hallahan DE 2006 Molecular strategies targeting the host component of cancer to enhance tumor response to radiation therapy. International Journal of Radiation Oncology, Biology, Physics 64 38-46.

Koutsilieris M, Mitsiades CS, Bogdanos J, Dimopoulos T, Karamanolakis D, Milathianakis C et al. 2004 Combination of somatostatin analog, dexamethasone, and standard androgen ablation therapy in stage D3 prostate cancer patients with bone metastases. Clinical Cancer Research 10 4398-4405. 
Lamberts SW, van der Lely AJ, de Herder WW \& Hofland LJ 1996 Octreotide. New England Journal of Medicine 334 246-254.

Landolt AM, Haller D, Lomax N, Scheib S, Schubiger O, Siegfried J \& Wellis G 2000 Octreotide may act as a radioprotective agent in acromegaly. Journal of Clinical Endocrinology and Metabolism $\mathbf{8 5}$ 1287-1289.

Luciani P, Gelmini S, Ferrante E, Lania A, Benvenuti S, Baglioni S, Mantovani G, Cellai I, Ammannati F, Spada A et al. 2005 Expression of the antiapoptotic gene seladin-1 and octreotide-induced apoptosis in growth hormonesecreting and nonfunctioning pituitary adenomas. Journal of Clinical Endocrinology and Metabolism 90 6156-6161.

Melen-Mucha G, Balcerczak E, Mucha S, Panczyk M, Lipa S \& Mirowski M 2004 Expression of p65 gene in experimental colon cancer under the influence of 5-fluorouracil given alone and in combination with hormonal modulation. Neoplasma $\mathbf{5 1}$ 319-324.

Miller GM, Alexander JM, Bikkal HA, Katznelson L, Zervas NT \& Klibanski A 1995 Somatostatin receptor subtype gene expression in pituitary adenomas. Journal of Clinical Endocrinology and Metabolism 80 1386-1392.

Pelicci G, Pagliacci MC, Lanfrancone L, Pelicci PG, Grignani F \& Nicoletti I 1990 Inhibitory effect of the somatostatin analog octreotide on rat pituitary tumor cell (GH3) proliferation in vitro. Journal of Endocrinological Investigation 13 657-662.

Pollock BE, Nippoldt TB, Stafford SL, Foote RL \& Abboud CF 2002 Results of stereotactic radiosurgery in patients with hormone-producing pituitary adenomas: factors associated with endocrine normalization. Journal of Neurosurgery 97 525-530.

Prevost G, Bourgeois Y, Mormont C, Lerrant Y, Veber N, Poupon MF et al. 1994 Characterization of somatostatin receptors and growth inhibition by the somatostatin analogue BIM23014 in small cell lung carcinoma xenograft: SCLC-6. Life Sciences 55 155-162.

Raderer M, Hamilton G, Kurtaran A, Valencak J, Haberl I, Hoffmann O, Kornek GV, Vorbeck F, Hejna MHL, Virgolini I et al. 1999 Treatment of advanced pancreatic cancer with the long-acting somatostatin analogue lanreotide: in vitro and in vivo results. British Journal of Cancer 79 535-537.

Rezacova M, Cap J, Vokurkova D, Lukasova E, Vavrova J, Cerman J, Masin V \& Mazankova N 2008 Effect of somatostatin on repair of ionizing radiation-induced DNA damage in pituitary adenoma cells GH3. Physiological Research 57 225-235.

Scaffidi C, Fulda S, Srinivasan A, Friesen C, Li F, Tomaselli KJ, Debatin KM, Krammer PH \& Peter ME 1998 Two CD95 (APO-1/Fas) signaling pathways. EMBO Journal 17 1675-1687.

Sharma K \& Srikant CB 1998 G protein coupled receptor signaled apoptosis is associated with activation of a cation insensitive acidic endonuclease and intracellular acidification. Biochemical and Biophysical Research Communications 242 134-140.

Sharma K, Patel YC \& Srikant CB 1996 Subtype-selective induction of wild-type p53 and apoptosis, but not cell cycle arrest, by human somatostatin receptor 3 . Molecular Endocrinology 10 1688-1696.

Shimon I, Taylor JE, Dong JZ, Bitonte RA, Kim S, Morgan B, Coy DH, Culler MD \& Melmed S 1997 Somatostatin receptor subtype specificity in human fetal pituitary cultures. Differential role of SSTR2 and SSTR5 for growth hormone, thyroid-stimulating hormone, and prolactin regulation. Journal of Clinical Investigation 99 789-798.

Theodoropoulou M, Zhang J, Laupheimer S, Paez-Pereda M, Erneux C, Florio T, Pagotto U \& Stalla GK 2006 Octreotide, a somatostatin analogue, mediates its antiproliferative action in pituitary tumor cells by altering phosphatidylinositol 3-kinase signaling and inducing Zac1 expression. Cancer Research 66 1576-1582.

Vainas IG 2001 Octreotide in the management of hormonerefractory prostate cancer. Chemotherapy 47 109-126.

Weckbecker G, Liu R, Tolcsvai L \& Bruns C 1992 Antiproliferative effects of the somatostatin analogue octreotide (SMS 201-995) on ZR-75-1 human breast cancer cells in vivo and in vitro. Cancer Research 52 4973-4978.

Zeytin FN, Gick GG, Brazeau P, Ling N, McLaughlin M \& Bancroft C 1984 Growth hormone $(\mathrm{GH})$-releasing factor does not regulate $\mathrm{GH}$ release or $\mathrm{GH}$ mRNA levels in $\mathrm{GH} 3$ cells. Endocrinology 114 2054-2059. 